\title{
The Innovation Mechanism of Industrial Clusters Based on the Cooperation of Intellectual Property
}

\author{
Deli Cheng \\ Room 1304, Tongji University, Siping Road, Shanghai, China
}

\begin{abstract}
The industrial clusters are an effective economy that has played an important role in promoting regional economy and crate employee opportunities. But for poor capability in applying and protecting intellectual property, china clusters are withering. The essay introduces the status quo of the clusters and analyses the reasons that lead to it. Put forth a strategic model about how to improve the innovation of industrial clusters in the perspective of intellectual property.
\end{abstract}

Keywords-intellectual; property industrial clusters; innovation

\section{INTRODUCTION}

The development of industrial cluster has become a worldwide economic phenomenon under the background of globalization knowledge economy. This specialized cluster is very outstanding in the developed countries. Due to a number of clusters in the whole world, they have formed a colorful and massive "Economic Mosaic", these clusters absorbed huge economic energy, and so that they cultivated a large number of world-class industries and enterprises. Frankly speaking, this phenomenon has been quite common in China for the broad sense, but compared with developed countries, there are also a lot of problems in our country, such that cluster innovation network is not mature, the kinetic energy is insufficient, the industrial park is not clustering, the cluster needs to expand and upgrade. Part of the clusters take on the shrinking steps in recent years, it has a great relationship with lack of innovation. All of this are because of not paying enough attention to the Intellectual property rights, doing not have a long-term strategy of IP rights. How to promote the cluster innovation which takes intellectual property rights as the gripper is the domain research in the industry economics, management, and the law field.

\section{The Problems of IP Rights IN The DeVelopment OF THE CLUSTER SYSTEM}

In the industrial cluster, most of them are related industries, enterprises, especially small and medium-sized enterprises gathered together, however, small and medium-sized enterprise is difficult to consider the application and manage intellectual property rights because of its financial resources of science and technology. Mainly manifested in the following aspects:

\section{A. Small and Medium-Sized Enterprise Don't Have Sufficient Understanding of IP Rights}

After a lot of research by WIPO's small and medium-sized enterprises department, it is obvious that whether the enterprise apply for a patent has a great relation with its scale, it is also serious that the use of IP rights for small and medium-sized enterprises is conditioned by the patent system, even for those enterprises relying on science and technology. In view of the small and medium-sized enterprises engaged in biotechnology according to the survey during Argentina, Brazil, Colombia, Chile and Uruguay, Only $6.7 \%$ of small and medium-sized enterprises will consider using state patent system. According to a study of small and medium enterprises by the association of south-east Asian nations indicates that they didn't realize the potential benefits of intellectual property rights, in the association of south-east Asian nation region, big companies and foreign companies typically control the field of intellectual property rights, especially patent field. This is especially true for science and technology enterprises in our country, a survey for small and mid-sized enterprise to Shanghai three players, 99.9\% of companies don't have intellectual property rights. This is because companies do not pay attention to the knowledge property rights.

\section{B. Small and Mid-Sized Enterprise Don't Take Full Advantage of Patent Information}

Small and medium-sized enterprises also don't have the strong will to make the best of patent information in the database. Various studies have shown the patent information as the proportion of science and technology information resources increases with the enterprise scale. The community innovation survey published by the European Union shows 34\% of ongoing research of large enterprises think patent information is important, and at the same time, the small and medium-sized enterprises of the data is only $18 \%$, and only $5.9 \%$ of medium-sized enterprises with no research development think that is important. The information provided by the supplier, the exhibition and the professional is still the main source for most companies.

\section{Patent Authorization Rate Is Low for Small and Mid-Sized Enterprise}

The study published by the WIPO on Norway's small and medium-sized enterprises about using the intellectual property system found another problem: the success rate of applying for a patent (patent authorization rate) is much smaller than large enterprises. The reasons of this situation are such as: small and medium-sized enterprises have relatively scarce technical information for first patent application, they could not be access to the enough legal advice , in the long process of an application for a patent ,they also lack of adequate human and financial resources, etc. 


\section{Many Small and Mid-sized Enterprise Still Tend to Protect Intellectual Property Rights Through Informal Channels}

A British study for computer software, design, electronic and electrical engineering industry has carried on the investigation, it found that the small and medium-sized enterprises focus on protecting intellectual property rights through informal channels. They think this way is more familiar, cheap, spending less time, and often considered to be more effective than formal ways to achieve the protection of intellectual property rights.

\section{THE REASONS OF TAKING NO COUNT OF IP RIGHTS FOR SMALL AND MEDIUM-SIZED ENTERPRISES IN THE INDUSTRY} CLUSTER

\section{A. Thinking that Intellectual Property Has Little to Do with the Company Development}

Many small and medium-sized enterprises believe that intellectual property development has little to do with the company, even not to mention combining intellectual property and enterprise business strategy. It is caused that small and medium-sized enterprises know little about intellectual property rights. Small and medium-sized enterprises generally thought that the patent system is too complex and expensive to use. The reasons are that the enterprise do not realize the value of the patent documents information; Enterprises also lack of patent retrieval skills; Enterprises are not familiar with the patent terms; And enterprises can not understand the "claim" in the patent document, etc.

\section{B. The Patent System Is Too Expensive and Complicated}

According to a survey by EPO, small and medium-sized enterprise fails to apply for a patent mainly because of the high cost of time consuming, and also some small and medium-sized enterprises pointed out that the existing patent system has low efficiency, the government failed to provide effective help in the process of application. Costs of patent is one of the biggest obstacles faced by the small and medium-sized enterprises.

\section{The Shortage of Fund for Enterprise Innovation}

For most of the small and mid-sized enterprises, money is the most scarce and valuable resource. These companies mainly reflected the value in intangible assets, which makes this kind of enterprises to obtain financial institutions, such as commercial Banks and risk investment, loan program is more complex. The European commission has commissioned a study, the difficult in intellectual property assets assessment is the main reason for being effective or indirect use of the assets. In this research according to the study of commercial Banks in Europe, no one is willing to accept the intangible assets such as intellectual property as collateral for the loan. As a result, we need to solve the problem of financing difficulties for small and medium-sized enterprises.

\section{The Implementation of Intellectual Property Issues}

In the process of analyzing the obstacles of using the intellectual property system, there is another factor to be considered, that is the problem of the implementation of intellectual property rights. How to monitor and perform the difficulties in the market for the protection of intellectual property rights is the key reason to hinder enterprises to apply for the protection. According to a study by European Union recently with the patents, $49 \%$ of the companies are fearing to pay the high cost of litigation, so as to affect the invention of direct investment.

\section{THE ENTERPRISE IP Rights STRATEGY DESIGNED BY USING THE MODEL}

Cluster intellectual property rights strategy emphasizes the development planning in order to promote the coordination of the industry. The cluster of intellectual property rights strategy is different with operational characteristics of enterprise intellectual property strategy, it emphasizes that in related industries it can promote the property capabilities of enterprise intellectual property and combine multi-dimensional subject by using the tools of intellectual property strategy. It is also different with the national intellectual property strategy and enterprise intellectual property strategy, intellectual property strategy presents the subject clarity, multiple tools, process control, complication and target multidimensional characteristics from the perspective of cluster innovation. On the basis of analyzing combination strategy of knowledge, To construct the model of intellectual property strategy based on industry cluster innovation (as shown in figure 1), at the same time to reveal the main body by using different tools in the use of intellectual property right strategy, and to probe into the implementation of intellectual property rights strategy of promoting innovation mechanism.

As shown in the Figure 1, the cluster strategy of intellectual property rights system composed of many subsystems. $\mathrm{S}$ is the main body of cluster innovation, including the government, enterprises, universities and research institutions, etc.; T means the tool, the use of methods of intellectual property rights: patent, trademark, copyright and other intellectual property rights, etc.; P represents process, four processes of intellectual property management : creation, management, protection and use. Due to the dynamics and openness of cluster industries, and the characteristics of industrial competitiveness of many factors, determines the different industry types, different stages of industrial development. Formulation and implementation need to be played by the role of the different intellectual property subject, they need control each process, combine different tools. Thus through formulation and implementation of the strategy, it is able to promote the competitiveness of the industry cluster.

Intellectual property subject, process and the tools actually form a three-dimensional network system. Through mathematical expressions we can be summarized the cluster subsystem of intellectual property rights strategy. As for S1 enterprise, $\mathrm{S} 1$ should perform $\mathrm{C} 1=\mathrm{S} 1 \mathrm{P} 1 \mathrm{~T} 1$ in the process of the creation of the intellectual property patent strategy. And as the similar way, the enterprises in the patent protection strategy should be C2 = S1P4T1, so for each main body, there is a policy set, different organic policy set to form clusters of intellectual property rights strategy. Different subject of intellectual property strategy use different tools of intellectual property rights in different policy choice, that is the cluster system through the process of intellectual property strategy. 


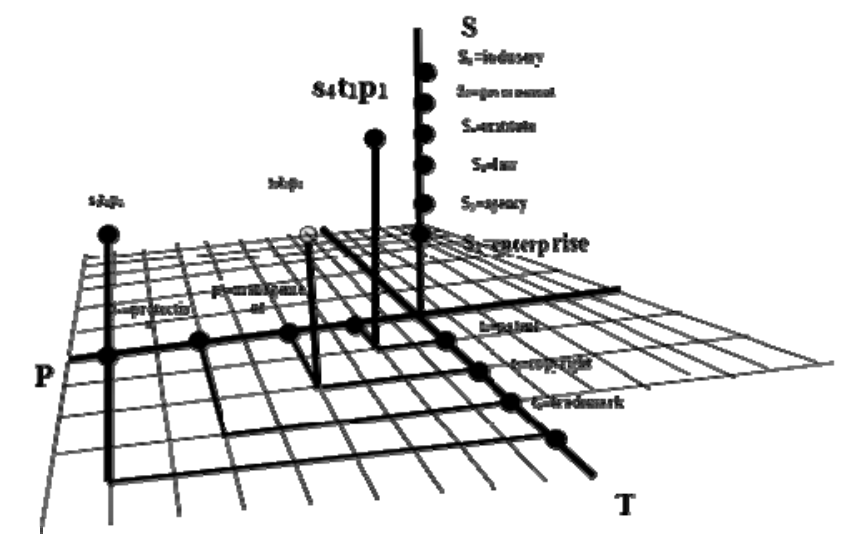

FIGURE I. THE CLUSTER STRATEGY OF INTELLECTUAL PROPERTY RIGHTS SYSTEM MODEL

\section{POLICIES AND MEASURES FOR PROMOTING THE IP} RightS OF SMALL AND MEDIUM-SIZED ENTERPRISE CLUSTER

\section{A. Further Strengthening the Cluster of Small and}

Medium-Sized Enterprises to Cooperate with Universities, Research Institutions

It suggests that the government further strengthen the small and medium-sized enterprises in collaboration with universities, research institutions. The police of IP Cluster should varies depending on the nature of cluster. The industrial clusters with innovation will drive and radiation in a region industry development. Therefore, the government should give special attention and protection in terms of creation, management, utilization and protection of intellectual property rights. To give guidance and help in the patent application aspect, the government should carry on the capital funding when it is necessary.

\section{B. Improving the Ability to Use and Management of the}

Technology-Based Small and Medium-Sized Enterprises in Cluster

It suggests various intellectual property management training courses should be held for different types of small and medium-sized enterprises. The content of the training course should not only teach the law, but also teach how to manage and use of intellectual property rights. For example, how to effectively combine intellectual property and business development planning, how to effectively develop intellectual property rights, how to make full use of the intellectual property strategy to expand the market, and so on. Personnel training makes the best of patent system, they should focus on the patent claim analysis, patent document retrieval, and avoiding the patent development creation again, such as the recombination of existing knowledge, etc. For example, with the help of Tongji university, intellectual property talent training can be operated well, etc.

\section{Further Improving the Information and Consulting Services in the Cluster}

Suggestions are that it should columns or a dedicated channels for small and medium-sized enterprises on the existing intellectual property website, and provide some practical information for small and medium-sized enterprises, including intellectual property introduction, the practical guide, the use of intellectual property cases, the best practices of intellectual property, etc.

\section{Strengthening the Ability of Innovation Cluster Supporting Its Own Intellectual Property Rights}

Government should fully attaches great importance to the innovation of cluster science park, incubators and other support institutions to foster and improve the ability of intellectual property rights. Especially creative industry cluster must have a certain amount of knowledge service, include the establishment of patent literature analysis, patent agency services, intellectual property rights trading office. Government also can be unified requirements for personnel of innovation clusters, for example, requiring the management office of industrial cluster to set up relevant institutions. Requiring the enterprise into the cluster to be equipped with a number of intellectual property management personnel, etc. Creative industry cluster involves a lot of intellectual property rights transfer, the industrialization of scientific and technological knowledge, so it involves many intellectual property interests among this assignment problem. Only mastering the law of intellectual property management, the core competitiveness of the cluster can be formed and maintained.

\section{ACKNOWLEDGEMENTS}

This article is one of the achievements for Shanghai social science fund project "Based on the research on innovation mode of regional intellectual property strategy”.

\section{REFERENCES}

[1] Michael .Porter, Cluster and economics of new competition, Harvard Rusinesc Review 1996.

[2] Yolanda. K. Gibb, Sam. Blili. Business Strategy and Governance of Intellectual Assets in Small \& Medium Enterprises Original Research Article. Procedia - Social and Behavioral Sciences, Volume 75, 3 April 2013, Pages 420-433.

[3] ZHAN Ying, WEN Bo. Industry Intellectual Property Strategy and the Formation of Industry Competitive Advantage----Taking India Software Industry as an Example. Science of Science and Management of S\&T. 2011(4).

[4] Sunil Kanwar, Robert Evenson. On the strength of intellectual property protection that nations provide Original Research Article. Journal of Development Economics, Volume 90, Issue 1, September 2009, Pages 50-56

[5] Johannes Liegsalz, Stefan Wagner. Patent examination at the State Intellectual Property Office in China Original Research Article. Research Policy, Volume 42, Issue 2, March 2013, Pages 552-563.

[6] Roberto M. Samaniego. Knowledge spillovers and intellectual property rights Original Research Article International Journal of Industrial Organization, Volume 31, Issue 1, January 2013, Pages 50-63.

[7] Brent Goldfarb, Magnus Henrekson. Bottom-up versus top-down policies towards the commercialization of university intellectual property Original Research Article. Research Policy, Volume 32, Issue 4, April 2003, Pages 639-658. 